\title{
Pushing the boundaries of surgery
}

The appropriate treatment of paranasal sinus and skull base malignancy is a controversial subject, particularly when new techniques are introduced. A number of articles in this issue of The Journal of Laryngology \& Otology discuss the application of modern techniques to complex and malignant disease of the paranasal sinuses. A frequent contention is whether endoscopic techniques to treat paranasal sinus neoplasia are superior to external approaches. To some extent this argument has been addressed with the recognition that both methods of treatment have their place, and that, importantly, they are not mutually exclusive in the same patient. Saedi and colleagues present surgical outcomes for malignant sinus tumours and show that overall survival rates in a group of 160 patients are no different in endoscopic compared with external approaches. ${ }^{1}$ They emphasise the importance of careful case selection based on tumour stage and operability.

Despite the obvious attractions of endoscopic approaches, there are cases in which an external approach to the anterior skull base and nasopharynx is necessary. Hussain and colleagues describe their modification of a midfacial translocation technique for access to ventral skull base tumours. ${ }^{2}$ They demonstrate that this approach can offer excellent surgical exposure with good aesthetic outcomes. Of particular importance is the preservation of the lip and bony piriform aperture. The surgical approach to this inaccessible area is a challenge, with endoscopic techniques also being feasible ${ }^{3}$ and facilitated by image guidance technology. ${ }^{4}$

Two articles in this issue of The Journal investigate additional areas of controversy. Conservative management of small vestibular schwannomas is now recognised as being the preferred option in the majority of cases. Management of larger tumours is more contentious; there is a greater likelihood that affected patients will be offered interventional treatment with surgery or stereotactic radiotherapy. Reddy and colleagues report a series of 45 patients with vestibular schwannomas measuring 15 to $31 \mathrm{~mm}$ in diameter. ${ }^{5}$ These were managed conservatively, and the outcomes were similar to those reported for smaller tumours. A previous report in The Journal documented spontaneous tumour shrinkage in a proportion of patients with vestibular schwannoma, ${ }^{6}$ substantiating conservative management of the majority of these tumours. Finally, an article in this issue addresses the psychosocial impact of otoplasty performed on children with prominent ears. $^{7}$ This is an important topic because this surgery can be labelled as purely cosmetic and hence rationed by healthcare providers. Songu and Kutlu demonstrated (with objective analysis using the Child Behavior Checklist) that psychological problems associated with prominent ears could be reduced by appropriate corrective surgery.

\section{ROBIN YOUNGS EDWARD FISHER Senior Editors}

\section{References}

1 Saedi B, Aghili M, Motiee M, Valadkhani S, Niazi AB, Safavi A. Surgical outcomes of malignant sinonasal tumours: open versus endoscopic surgical approaches. J Laryngol Otol 2014;128: 784-790

2 Hussain A, Shakeel M, Vallamkondu V, Kamel M. Modified midfacial translocation for access to ventral skull base tumours. J Laryngol Otol 2014;128:803-809

3 Kantola VE, McGarry GW, Rea PM. Endonasal, transmaxillary, transpterygoid approach to the foramen ovale: radio-anatomical study of surgical feasibility. J Laryngol Otol 2013;127:1093-102

4 Visvanathan V, McGarry GW. Image guidance in rhinology and anterior skull base surgery: five-year single institution experience. $J$ Laryngol Otol 2013;127:159-62

5 Reddy CEE, Lewis-Jones HG, Javadpour M, Ryland I, Lesser THJ. Conservative management of vestibular schwannomas of 15 to $31 \mathrm{~mm}$ intracranial diameter. J Laryngol Otol 2014;128: $752-758$

6 Huang X, Caye-Thomasen P, Stangerup S-E. Spontaneous tumour shrinkage in 1261 observed patients with sporadic vestibular schwannoma. J Laryngol Otol 2013;127:739-43

7 Songu M, Kutlu A. Long-term psychosocial impact of otoplasty performed on children with prominent ears. J Laryngol Otol 2014;128:768-771 